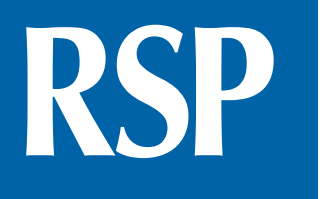

http://www.rsp.fsp.usp.br/
Revista de Saúde Pública

\title{
Life expectancy without depression increases among Brazilian older adults
}

Flávia Cristina Drumond Andrade', Fan Wu", Maria Lúcia Lebrão"II, Yeda Aparecida de Oliveira Duarte ${ }^{\mathrm{IV}}$

I Department of Kinesiology and Community Health. College of Applied Health Sciences. University of Illinois at Urbana-Champaign. Champaign, IL, EUA

" San Francisco Department of Public Health. Community Behavioral Health Services. San Francisco, CA, EUA

II' Departamento de Epidemiologia. Faculdade de Saúde Pública. Universidade de São Paulo. São Paulo, SP, Brasil

Iv Departamento de Enfermagem Médico-Cirúrgica. Escola de Enfermagem. Universidade de São Paulo. São Paulo, SP, Brasil

\section{ABSTRACT}

OBJECTIVE: To estimate life expectancy with and without depressive symptoms in older adults for the years 2000 and 2010.

METHODS: We evaluated individuals aged 60 years or older ( $\mathrm{n}=1,862$ in 2000 and $\mathrm{n}=1,280$ in 2010), participants of the Saúde, Bem-Estar e Envelhecimento (SABE - Health, Wellbeing and Aging) study in in Sao Paulo, Southeastern Brazil. Depression was measured using the shorter version of the Geriatric Depression Scale (GDS-15); respondents scoring $\geq 6$ were classified as having depression. Estimates of life expectancy with and without depression were obtained using the Sullivan method.

RESULTS: Data from 2000 indicate that 60-year-old men could expect to live, on average, 14.7 years without depression and 60-year-old women could expect to live 16.5 years without depression. By 2010, life expectancy without depression had increased to 16.7 years for men and 17.8 years for women. Expected length of life with depression differed by sex, with women expected to live more years with depression than men.

CONCLUSIONS: Between 2000 and 2010, life expectancy without depression in Sao Paulo increased. However, older adults in Brazil, especially older women, still face a serious burden of mental illness.

Flávia Cristina Drumond Andrade

1206 S. 4th Street

2011 Huff Hall

61822 Champaign, IL, USA

E-mail: fandrade@illinois.edu

Received: 06 Oct 2014

Approved: 30 May 2015

How to cite: Andrade FCD, Wu F, Lebrão ML, Duarte YAO. Life expectancy without depression increases among Brazilian older adults. Rev Saude Publica.

2016;50:12

Copyright: This is an open-access article distributed under the terms of the Creative Commons Attribution License, which permits unrestricted use, distribution, and reproduction in any medium, provided that the original author and source are credited.

DESCRIPTORS: Aged. Life Expectancy. Aging. Depression, epidemiology. Gender and Health. Health Surveys. 


\section{INTRODUCTION}

Depression is a common mental health condition among older adults in Brazil. Researchers have estimated that more than $25.0 \%$ of community-dwelling older adults in Brazil have clinically significant depressive symptoms and $7.0 \%$ have major depression ${ }^{4}$. These rates are even higher among older adults who are hospitalized or living in long-term facilities. A recent meta-analysis found that the prevalence of clinically significant depressive symptoms varied from 20.0\%-56.0\% among hospitalized older adults in Brazil, and the rates among older adults in long-term care facilities varied from $11.0 \%-65.0 \%{ }^{11}$. Chisholm et al. ${ }^{12}$ estimated that it would cost US\$170 per capita per year to cover the direct expenses of treating individuals with subclinical depression in the Country.

Experiencing depression at an older age has important implications for individuals, families and society. Among older adults, depression causes individual and family suffering and is associated with poor adherence to recommended medical treatment ${ }^{15}$, poor lifestyle behaviors ${ }^{34}$, cognitive impairment ${ }^{24}$, and physical disability9,27. In turn, these factors are associated with lower quality of life ${ }^{7,16}$, higher level of health care use ${ }^{7,8}$, and higher mortality rates ${ }^{28}$.

Many factors can trigger the onset of depressive symptoms among older adults. Medical disorders such as cancer, metabolic disorder, heart disease, and stroke are commonly associated with depressive symptoms ${ }^{28}$. Limitations in daily activities, cognition, and mobility as well as social changes (such as retirement, bereavement, social isolation, and relocation) also influence mood and distress, leading to depressive symptoms. Because the prevalence of these conditions increases with age, researchers and policy makers should not overlook depressive symptoms among the older population.

Life expectancy among older adults in Brazil has increased in recent decades. Life expectancy at birth increased from 51 to 72 years from 1950-2010, and is expected to reach 77.4 years by $2030^{\mathrm{a}}$. During the same period, the proportion of older adults grew from $5.0 \%$ of the total population to about $10.0 \%$. By 2030 , the older adult population is expected to more than double, reaching 40.7 million people or $17.1 \%$ of the total Brazilian population ${ }^{\mathrm{b}}$.

While previous studies have provided important estimates of the prevalence of clinically significant depressive symptoms and major depressive symptoms among older adults in Brazil, as well as the factors associated with those conditions, to the best of our knowledge, no studies have estimated the length of life with depressive symptoms, information that would help researchers and policy makers better understand the burden of this condition for this fast-aging society. Given that life expectancy among older adults in Brazil has increased in recent decades, estimates of life expectancy with and without depression are critical to the accurate determination of current and future social and medical service needs.

In this study, we estimated life expectancy with and without depressive symptoms among older adults for the years 2000 and 2010.

${ }^{a}$ Comisión Económica para América Latina y el Caribe. Mortalidad. Observatório Demográfico. 2007;2(4). Available from: http://www. cepal.org/publicaciones/ xml/9/33269/OD-4-contentsintroduction.pdf

${ }^{\mathrm{b}}$ Comisión Económica para América Latina y el Caribe. Proyecciones de población. Observatório Demográfico. 2012. Available from: http:// repositorio.cepal.org/bitstream/ handle/11362/7118/S2012922 mu.pdf?sequence $=1$

\section{METHODS}

This study analyzed data from the Saúde, Bem-Estare Envelhecimento (SABE - Health, Wellbeing and Aging) survey, a longitudinal study of a probabilistic sample of older adults (age 60 and older) of both sexes living in the city of Sao Paulo, SP, Southeastern Brazil. The first wave of the SABE survey was conducted in 2000 with a sample of 2,143 respondents obtained using a two-stage stratified sampling method. Individuals aged 75 or older were oversampled to compensate for the groups higher mortality rate and smaller probability of being sampled. Details of the study sampling methodology can be found elsewhere ${ }^{22}$. In 2006, a second wave of data was collected $(n=1,413)$. The sample for the follow-up data collection included the 
1,115 older adults from the baseline study and 298 new respondents age 60-64. Data collection procedures were the same as in the baseline study. In 2010, a third wave of data was collected $(n=1,345)$. Three groups participated in that wave: a) 748 respondents from the baseline study, b) 242 respondents from the 2006 study, and c) 355 new respondents age- 64 .

The study reported here focuses on the cross-sectional prevalence rates of depression estimated from data obtained in 2000 and 2010. Sample weights for 2000 were calculated based on the 2000 census and weights for the 2010 sample were based on the 2010 census.

Depression was measured using the shorter version of the Geriatric Depression Scale (GDS-15) in the SABE survey. The GDS- 15 short form was based on the GDS- $30^{37}$ and has been widely used in clinical and population-based studies as a screening instrument for late-life depression. Several studies have analyzed the scales validity and reliability, and have found that the instrument has good specificity and sensitivity ${ }^{30}$. SABE used a GDS-15 questionnaire validated for use in Brazil ${ }^{1}$. Individuals with missing data on more than five items were excluded from the analysis. We used prorated procedures to estimate scores for respondents with missing data on five or fewer items. The Cronbach's alpha coefficient for the total scale was 0.82 for both years. We used a GDS- 15 cutoff score of $\geq 6$ points to classify individuals as having depression ${ }^{1}$.

Mortality data were obtained from the Fundação Sistema Estadual de Análise de Dados (SEADE Foundation - State System for Data Analysis Foundation)c, which provides data on social, demographic, and economic status for the State of Sao Paulo. We generated estimates for 2000 and 2010 using the 1999-2000-2001 and 2009-2010-2011 tables.

Sex was included as a covariate when disaggregating the data, given sex differences in mortality and prevalence of depressive symptoms. We estimated prevalence rates and $95 \%$ confidence intervals using sampling weights with Stata-SE version 12.1. Logistic regressions were used to assess sex and wave-related differences.

The Sullivan method (Sullivan, 1997) was used to estimate life expectancy with and without depression. The method employs a standard life table with two states, alive and dead. The alive state is subdivided into two categories, healthy (nondepressed) and unhealthy (depressed), using data on the observed prevalence of depression ${ }^{6,22, d}$. The major inputs are the age-specific prevalence of depressed and nondepressed states in the population and age-specific mortality rates. The expected years in the nondepressed state and expected years in the depressed state were estimated by applying the age- and sex-specific cross-sectional prevalence rates for nondepressed and depressed respondents, respectively, to the person-years lived in different age groups (derived from the period life tables).

Healthy Life Expectancy (HLE) $\frac{\Sigma\left(1-n \pi_{x}\right) n L_{x}}{l_{x}}$ and

Life Expectancy with Depression $_{\mathrm{x}} \frac{\sum\left(\mathrm{n} \pi_{x}\right) \mathrm{nL} x}{l_{x}}$

Healthy life expectancy (HLE) is the average number of years an individual is expected to live without depression, starting at an exact age $\mathrm{x}$; life expectancy with depression represents the average number of years an individual is expected to live with depression, starting at an exact age $\mathrm{x}$. To calculate HLE and life expectancy with depression, we used the prevalence of depression for individuals aged $\mathrm{x}$ to $\mathrm{x}+\mathrm{n}\left(\mathrm{n}_{\mathrm{x}}\right)$ (obtained from the SABE survey), the total number of years of life expectancy for individuals aged $x$ to $x+n\left({ }_{n} L_{x}\right)$, and the survival probability for exact age $x$ $\left(\mathrm{l}_{\mathrm{x}}\right)$. The last two variables were obtained from the life table generated from estimates provided by SEADE. Total life expectancy (TLE) is the sum of healthy (HLE) and unhealthy years of life. These estimates are independent of the age structure of the population.

The SABE survey was approved by the Research Ethics Committee of the Faculdade de Saúde Pública, Universidade de São Paulo, Brazil (Process: 67/99) and by the Brazilian 
National Ethics Committee (Process 315/99). Participation in the study was voluntary, and each respondent signed an informed consent form. The present study was approved by the Institutional Review Board at the University of Illinois.

\section{RESULTS}

In 2000 and 2010, respectively, 281 (13.1\%) and 65 subjects (4.8\%) had missing data on depressive symptoms. In both years, those with missing data were older than those with complete data (in 2000, 80.8 years versus 72.1, $\mathrm{p}<0.001$; in 2010, 83.5 years versus 72.3, $\mathrm{p}<0.001$ ); however, there were no sex differences between the two groups.

Table 1 shows the results related to the prevalence of depression in 2000 and 2010 (weighted estimates) in the Sao Paulo population of older adults. Among the 1,862 participants in the 2000 sample, $21.8 \%$ (95\%CI 19.7-24.0) were categorized as having depression (i.e., scored 6 or more on the GDS scale). The prevalence rate did not change over time:21.1\%(95\%CI 18.8-23.6) of the 1,280 older adults in the 2010 sample were categorized as having depression. In the logistic regression models (results not shown, but available upon request), depression was more common among women than among men in both periods, even after controlling for age $(\mathrm{p}<0.0001)$. The depression rate for men was $16.3 \%$ in 2000 and $14.4 \%$ in 2010, whereas the rate for women was about one fourth of the population in each year (25.7\% in 2000 and $25.2 \%$ in 2010).

TLE increased in Sao Paulo from 2000 to 2010 for both men and women (Table 2). TLE at age 60 increased from 17.5 years to 19.4 years for men and from 22.0 years to 23.7 years for women. The estimated average number of years lived without depression also increased. Among men, HLE at age 60 was 14.7 years in 2000 and 16.7 years in 2010, an increase of two years. Among women, the gain was smaller: HLE at age 60 was 16.5 years in 2000 and 17.8 years in 2010 .

Table 1. Prevalence and 95\%Cl of depression among older adults in Sao Paulo, Brazil: 2000 and 2010 (weighted estimates).

\begin{tabular}{|c|c|c|c|c|}
\hline \multirow{2}{*}{ Sex and age groups } & \multicolumn{2}{|c|}{2000} & \multicolumn{2}{|c|}{2010} \\
\hline & $\%$ & $95 \% \mathrm{Cl}$ & $\%$ & $95 \% \mathrm{Cl}$ \\
\hline All participants & 21.8 & $19.7-24.0$ & 21.1 & $18.8-23.6$ \\
\hline $60-64$ & 21.4 & $17.7-25.7$ & 23.3 & $18.9-28.3$ \\
\hline $65-69$ & 24.5 & $20.3-29.2$ & 15.1 & $10.8-20.6$ \\
\hline $70-74$ & 21.3 & $17.0-26.4$ & 20.6 & $15.5-26.9$ \\
\hline $75-79$ & 18.7 & $15.0-23.1$ & 23.7 & $17.3-31.5$ \\
\hline $80-84$ & 16.9 & $12.4-22.7$ & 22.8 & $16.3-30.8$ \\
\hline$\geq 85$ & 23.0 & $15.1-33.4$ & 22.0 & $16.0-29.5$ \\
\hline Males & 16.3 & $13.4-19.6$ & 14.4 & $11.2-18.2$ \\
\hline $60-64$ & 14.6 & $10.0-21.0$ & 15.3 & $9.8-23.2$ \\
\hline $65-69$ & 17.7 & $12.1-25.2$ & 8.5 & $3.7-18.1$ \\
\hline $70-74$ & 19.5 & $13.1-27.9$ & 11.0 & $5.3-21.5$ \\
\hline $75-79$ & 14.4 & $9.9-20.7$ & 17.4 & $8.8-31.4$ \\
\hline $80-84$ & 13.1 & 7.9-20.9 & 14.8 & $6.7-29.5$ \\
\hline$\geq 85$ & 11.9 & $5.6-23.5$ & 21.5 & $13.0-33.3$ \\
\hline Females & 25.7 & $22.9-28.7$ & 25.2 & $22.1-28.5$ \\
\hline $60-64$ & 26.8 & $21.5-32.8$ & 28.6 & $22.7-35.4$ \\
\hline $65-69$ & 29.5 & $23.9-35.9$ & 19.0 & $13.2-26.4$ \\
\hline $70-74$ & 22.5 & $17.1-29.2$ & 25.9 & $19.1-34.2$ \\
\hline $75-79$ & 21.4 & $16.3-27.5$ & 27.1 & $19.0-37.1$ \\
\hline $80-84$ & 18.9 & $12.8-26.9$ & 26.3 & $18.2-36.4$ \\
\hline$\geq 85$ & 29.7 & $18.3-44.5$ & 22.5 & $14.8-32.8$ \\
\hline
\end{tabular}


Table 2. Total life expectancy (TLE) and life expectancy without depression (HLE) among older adults in Sao Paulo, Brazil: 2000 and 2010.

\begin{tabular}{|c|c|c|c|c|c|c|c|c|c|c|}
\hline \multirow[b]{2}{*}{ Sex and age } & \multicolumn{5}{|c|}{2000} & \multicolumn{5}{|c|}{2010} \\
\hline & TLE & HLE & $95 \% \mathrm{Cl}$ & $\begin{array}{c}\% \text { of } \\
\text { remaining } \\
\text { years without } \\
\text { depression }\end{array}$ & $\begin{array}{c}\text { Life } \\
\text { expectancy } \\
\text { with } \\
\text { depression }\end{array}$ & TLE & HLE & $95 \% \mathrm{Cl}$ & $\begin{array}{c}\% \text { of } \\
\text { remaining } \\
\text { years without } \\
\text { depression }\end{array}$ & $\begin{array}{c}\text { Life } \\
\text { expectancy } \\
\text { with } \\
\text { depression }\end{array}$ \\
\hline \multicolumn{11}{|l|}{ Total } \\
\hline 60 & 20.0 & 15.7 & $14.7-16.6$ & 78.7 & 4.3 & 21.6 & 17.1 & $15.7-18.2$ & 79.0 & 4.5 \\
\hline 65 & 16.5 & 13.0 & $12.1-13.8$ & 78.7 & 3.5 & 17.9 & 14.3 & $13.1-15.3$ & 79.7 & 3.6 \\
\hline 70 & 13.4 & 10.7 & 9.9-11.4 & 79.9 & 2.7 & 14.5 & 11.3 & $10.3-12.2$ & 77.8 & 3.2 \\
\hline 75 & 10.5 & 8.5 & $7.8-9.0$ & 80.6 & 2.0 & 11.4 & 8.8 & $7.9-9.5$ & 77.1 & 2.6 \\
\hline 80 & 8.1 & 6.5 & $5.8-7.0$ & 80.1 & 1.6 & 8.7 & 6.8 & $6.1-7.3$ & 77.6 & 2.0 \\
\hline 85 & 6.1 & 4.7 & $4.1-5.2$ & 77.0 & 1.4 & 6.4 & 5.0 & $4.5-5.4$ & 78.0 & 1.4 \\
\hline \multicolumn{11}{|l|}{ Males } \\
\hline 60 & 17.5 & 14.7 & 13.4-15.6 & 84.0 & 2.8 & 19.4 & 16.7 & 14.6-17.9 & 86.1 & 2.7 \\
\hline 65 & 14.3 & 12.0 & $10.8-12.8$ & 83.7 & 2.3 & 16.0 & 13.8 & $12.0-14.9$ & 86.5 & 2.2 \\
\hline 70 & 11.5 & 9.7 & 8.8-10.4 & 84.6 & 1.8 & 12.8 & 10.9 & $9.3-11.8$ & 85.0 & 1.9 \\
\hline 75 & 9.1 & 7.9 & $7.1-8.3$ & 86.5 & 1.2 & 10.1 & 8.3 & 6.9-9.1 & 82.0 & 1.8 \\
\hline 80 & 7.0 & 6.1 & $5.4-6.5$ & 87.3 & 0.9 & 7.7 & 6.3 & $5.3-7.0$ & 82.4 & 1.4 \\
\hline 85 & 5.4 & 4.8 & $4.1-5.1$ & 88.3 & 0.6 & 5.7 & 4.5 & $3.8-5.0$ & 78.9 & 1.2 \\
\hline \multicolumn{11}{|l|}{ Females } \\
\hline 60 & 22.0 & 16.5 & 14.8-17.9 & 75.0 & 5.5 & 23.7 & 17.8 & $15.7-19.4$ & 75.0 & 5.9 \\
\hline 65 & 18.2 & 13.7 & $12.3-14.9$ & 75.5 & 4.5 & 19.6 & 14.9 & $13.2-16.3$ & 76.2 & 4.7 \\
\hline 70 & 14.7 & 11.3 & $10.1-12.3$ & 77.0 & 3.4 & 15.9 & 11.8 & $10.3-13.1$ & 74.5 & 4.1 \\
\hline 75 & 11.5 & 8.8 & 7.7-9.6 & 76.6 & 2.7 & 12.4 & 9.3 & $8.0-10.3$ & 75.0 & 3.1 \\
\hline 80 & 8.7 & 6.5 & $5.6-7.3$ & 75.3 & 2.2 & 9.4 & 7.1 & $6.2-7.9$ & 75.8 & 2.3 \\
\hline 85 & 6.5 & 4.5 & $3.6-5.3$ & 70.0 & 2.0 & 6.8 & 5.3 & $4.6-5.8$ & 77.5 & 1.5 \\
\hline
\end{tabular}

e Klugman J. Human

development report 2011:

sustainability and equity: a better

future for all. (November 2,

2011). UNDP-HDRO Human

Development Reports, 2011.

Available from: http://ssrn.com/

abstract $=2294671$
In both 2000 and 2010, the ratio of healthy years to total years was higher for men than for women. This result suggests that although women lived longer than men, on average, women were more likely to spend a higher percentage of their remaining lives with depression than men. Both men and women experienced very little change in life expectancy with depression over time. On average, women at age 60 were expected to live 5.5 years with depression in 2000 and 5.9 years in 2010. For men at age 60, life expectancy with depression was 2.8 years in 2000 and 2.7 years in 2010.

\section{DISCUSSION}

Findings show that from 2000-2010, both TLE and life expectancy without depression increased among older adults in Sao Paulo, which may reflect living more years with higher quality of life, less disability, and better health status ${ }^{28}$. Given the association between depression and mortality, the recent gains in life expectancy without depression can increase TLE by reducing the number of premature deaths due to several causes (e.g., suicide).

Life expectancy and HLE are related to economic and social capital as well as social inequalities. In Brazil, the 2000-2010 period was marked by economic growth, improvements in social indicators, and reductions in social inequalities. According to the World Bank's World Development Indicators database, per capita gross domestic product (measured in US dollars at 2005 prices) grew from US $\$ 4,407$ in 2000 to US\$5,618 in $2010^{26}$. The human development index, a composite measure including health, schooling, and income, has also improved in Brazil over recent decades ${ }^{e}$. The Gini coefficient, a measure of income inequality ranging from 0 (complete equality) to 1 (complete inequality), fell from 0.59 in 2000 to 0.54 in 2009 . 
These values indicate a favorable change in several social and economic factors, which may have increased both TLE and life expectancy without depression.

The results support previous findings showing a higher prevalence of depression and depressive symptoms among older women than among older men in developing countries, including Brazil ${ }^{3,4,20,32}$. A larger proportion of older women than older men in Sao Paulo have depression and women can expect to live a higher proportion of their remaining lives with depression than men. These findings are consistent with previous research on life expectancy and HLE, which has found that even though women live longer lives, they live more years with health problems such as disability, cognitive impairment, and mental health problems ${ }^{2}$.

This study has some limitations. First, the measure of depression prevalence differed from the measure used in other studies. In this study, participants' depressive symptoms were reported using the GDS 15-item subscale, and we used a cutoff score of 6. Other studies on the prevalence of depressive symptoms among Brazilians have used other measures, different cutoff points, or alternative ways of dealing with item nonresponse, all of which influence the estimated prevalence rate. For example, our estimate was higher than a previous estimate of the depression rate for older adults in Sao Paulo from 2002-2004 (22.0\% versus 13.0\%) measured depression based on questions from the GDS-30 and the Center for Epidemiologic Studies Depression Scale (CES-D 10) ${ }^{17,33}$. The current results also differ from the original SABE reports ${ }^{19}$, which used different procedures for handling item nonresponse. Finally, our results were lower than the ones of a meta-analysis that reported a $26.0 \%$ prevalence of clinically significant depressive symptoms among older community-dwelling adults in Brazil ${ }^{4}$.

A second limitation of the study is related to the data collection procedures for depressive symptoms; these symptoms were self-reported by those who were cognitively intact, but those with cognitive limitations ( $\mathrm{n}=198$ in 2000 and $\mathrm{n}=196$ in 2010) failed to provide information on depressive symptoms. Although missing data could also be considered an important limitation, when we compared the characteristics of respondents with missing data and those with no missing data (at baseline), only age differed significantly. In further analyses (results not shown, but available upon request), we imputed data for those with missing information on more than five items. Imputed prevalence rates differed slightly from the rates used in the study ( $21.2 \%$ versus $21.8 \%$ in 2000 , respectively, and $21.7 \%$ versus $21.1 \%$ in 2010 , respectively). When imputed values were calculated separately by sex, differences remained small, with all imputed prevalence rates decreasing slightly, except the rate for women in 2010 (imputed rate was $25.9 \%$, compared with the $25.2 \%$ rate used in the analyses). Even when separated by sex, all imputed values were within the confidence intervals presented in Table 2.

A third limitation of the study is that estimates of depression may be biased because we did not include respondents living in nursing homes at baseline and depression may be higher among this segment of the population. However, this population in Brazil is small - about 1.0\% according to Camarano and $\mathrm{Kanso}^{10}$ and $0.5 \%$ according to the SABE survey; therefore, this bias is likely trivial.

Other limitations originate from the application of the Sullivan method. We employed the Sullivan method because the goal of the article was to evaluate trends over time in life expectancy with and without depression. However, we used a stationary population approach to interpret the estimates produced via Sullivan method, and thus results should be interpreted with caution because the data are dependent on past conditions of the population ${ }^{22}$. Another potential issue related to using mortality rates from life tables is that we did not formally account for the association between depression and increased mortality risk $^{25}$. An alternative to the current analytical strategy would be to incorporate mortality by health state and health transitions (i.e., incidence and recovery) using multistate life tables $^{21}$. However, as shown in other settings, longitudinal surveys tend to underestimate deaths as a result of the omission of respondents living in nursing homes in the baseline data as well as the potential of missing deaths in follow-up waves ${ }^{18,29}$. Finally, due to the lack of nationally representative data on the depression prevalence in Brazil, the results from this 
study reflect only the experiences of older adults in Brazil's largest city, which may differ from the experiences of older people throughout the Country.

Life expectancy without depression increased from 2000 to 2010 in Sao Paulo. Further improvements in quality of life can be obtained by early diagnosis and treatment of individuals with depression. However, the underdiagnosis of depression is a serious health problem, particularly in countries such as Brazil in which many residents lack adequate access to healthcare services for diagnosis and treatment. In order to expand services and healthcare, the number of mental health care workers must increase, and access to care must improve.

Given the limited resources available, community and primary health workers can be trained to perform some roles under the supervision of specialists. Some authors have called for "task shifting" programs in which nonspecialists can complete certain tasks, such as identifying cases, providing referrals, supporting medication adherence, and delivering psychosocial treatment ${ }^{13,15}$. Given the associations between mental health conditions and other health conditions, integrating mental health care into general health care is another change that has the potential to improve outcomes ${ }^{13}$. In Brazil, the current Política Nacional de Saúde do Idoso (PNSI - National Policy for the Health of the Elderly) seeks to improve older adults' health and well-being through improved immunization and distribution of medication ${ }^{23}$. A more diverse and larger workforce is also needed to deliver interventions aimed at modifying behaviors - such as physical exercise - that can improve the health outcomes of individuals with depressive symptoms ${ }^{5}$.

Finally, other innovations may involve using technology to improve medical care by expanding training and improving access to care and treatment in Brazil. Ultimately, empowering Brazilian individuals with depression and their families can lead to additional advocacy for better services, improved social inclusion, and reduced stigma ${ }^{13}$. All of these changes have the potential to facilitate early diagnosis, better treatment, and increased healthy life expectancy.

\section{REFERENCES}

1. Almeida OP, Almeida SA. Confiabilidade da versão brasileira da Escala de Depressão em Geriatria (GDS) versão reduzida. Arq Neuropsiquiatr. 1999;57(2B):421-6. DOI:10.1590/S0004-282X1999000300013

2. Andrade FC, Corona LP, Lebrão ML, Duarte YA. Life expectancy with and without cognitive impairment among Brazilian older adults. Arch Gerontol Geriatr. 2014;58(2):219-25. DOI:10.1016/j.archger.2013.10.007

3. Barcelos-Ferreira R, Pinto Junior JA, Nakano EY, Steffens DC, Litvoc J, Bottino CMC. Clinically significant depressive symptoms and associated factors in community elderly subjects from Sao Paulo, Brazil. Am J Ger Psychiatry. 2009;17(7):582-90. DOI:10.1097/JGP.0b013e3181a76ddc

4. Barcelos-Ferreira R, Izbicki R, Steffens DC, Bottino C. Depressive morbidity and gender in community-dwelling Brazilian elderly: systematic review and meta-analysis. Int Psychogeriatr. 2010;22(05):712-26. DOI:10.1017/S1041610210000463

5. Barcelos-Ferreira R, Yoshio Nakano E, Steffens DC, Bottino CMC. Quality of life and physical activity associated to lower prevalence of depression in community-dwelling elderly subjects from Sao Paulo. J Affect Disord. 2013;150(2):616-22. DOI:10.1016/j.jad.2013.02.024

6. Barendregt JJ. Incidence- and prevalence-based SMPHs: making the twain meet. In: Murray CJL, Salomon JA, Mathers CD, Lopez AD, editors. Summary measures of population health: concepts, ethics, measurement and applications. Geneva: World Health Organization; 2002. p. 221-31.

7. Beekman AT, Penninx BW, Deeg DJ, Beurs E, Geerlings SW, Tilburg W. The impact of depression on the well being, disability and use of services in older adults: a longitudinal perspective. Acta Psychiatr Scand. 2002;105(1):20-7. DOI:10.1034/j.1600-0447.2002.10078.x

8. Bhattarai N, Charlton J, Rudisill C, Gulliford MC. Prevalence of depression and utilization of health care in single and multiple morbidity: a population-based cohort study. Psychol Med. 2013;43(7):1423-31. DOI:10.1017/S0033291712002498 
9. Bruce ML, Seeman TE, Merrill SS, Blazer DG. The impact of depressive symptomatology on physical disability: MacArthur studies of successful aging. Am J Public Health. 1994;84(11):1796-9. DOI:10.2105/AJPH.84.11.1796

10. Camarano AA, Kanso S. As instituições de longa permanência para idosos no Brasil. Rev Bras Estud Popul. 2010;27(1):232-5. DOI:10.1590/S0102-30982010000100014

11. Castro-de-Araujo LFS, Barcelos-Ferreira R, Martins CB, Bottino C. Depressive morbidity among elderly individuals who are hospitalized, reside at long-term care facilities, and are under outpatient care in Brazil: a meta-analysis. Rev Bras Psiquiatr. 2013;35(2):201-7. DOI:10.1590/1516-4446-2012-0905

12. Chisholm D, Diehr P, Knapp M, Patrick D, Treglia M, Simon G et al. Depression status, medical comorbidity and resource costs: evidence from an international study of major depression in primary care (LIDO). Br J Psychiatry. 2003;183(2):121-31. DOI:10.1192/bjp.183.2.121

13. DeSilva M, Samele C, Saxena S, Patel V, Darzi A. Policy actions to achieve integrated community-based mental health services. Health Aff (Millwood). 2014;33(9):1595-602. DOI:10.1377/hlthaff.2014.0365

14. DiMatteo MR, Lepper HS, Croghan TW. Depression is a risk factor for noncompliance with medical treatment: meta-analysis of the effects of anxiety and depression on patient adherence. Arch Intern Med. 2000;160(14):2101-7. DOI:10.1001/archinte.160.14.2101

15. Fairburn CG, Patel V. The global dissemination of psychological treatments: a road map for research and practice. Perspectives. 2014;171(5):495-8. DOI:10.1176/appi.ajp.2013.13111546

16. Joffe H, Chang Y, Dhaliwal S, Hess R, Thurston R, Gold E et al. Lifetime history of depression and anxiety disorders as a predictor of quality of life in midlife women in the absence of current illness episodes. Arch Gen Psychiatry. 2012;69(5):484-92. DOI:10.1001/archgenpsychiatry.2011.1578

17. Kohout FJ, Berkman LF, Evans DA, Cornoni-Huntley J. Two shorter forms of the CES-D depression symptoms index. J Aging Health. 1993: 5:179-93. DOI: 10.1177/089826439300500202

18. Kristman V, Manno M, Côté P. Loss to follow-up in cohort studies: how much is too much? Eur J Epidemiol. 2004;19(8):751-60. DOI:10.1023/B:EJEP.0000036568.02655.f8

19. Lebrão ML, Laurenti R. Saúde, bem-estar e envelhecimento: o estudo SABE no município de São Paulo. Rev Bras Epidemiol. 2005;8(2):127-41. DOI:10.1590/S1415-790X2005000200005

20. Li D, Zhang D, Shao J, Qi X, Tian L. A meta-analysis of the prevalence of depressive symptoms in Chinese older adults. Arch Gerontol Geriatr. 2014;58(1):1-9. DOI:10.1016/j.archger.2013.07.016

21. Lievre A, Alley D, Crimmins EM. Educational differentials in life expectancy with cognitive impairment among the elderly in the United States. J Aging Health. 2008;20(4):456-77. DOI:10.1177/0898264308315857

22. Mathers C. Health expectancies: an overview and critical appraisal. In: Murray C, Salomon JA, Mathers CD, Lopez AD, editors. Summary measures of population health: concepts, ethics, measurement and applications. Geneva: World Health Organization; 2002. p.177-204.

23. Miyata DF, Vagetti GC, Fanhani HR, Pereira JG, Andrade OG. Políticas e programas na atenção à saúde do idoso: um panorama nacional. Arq Cienc Saude Unipar. 2005;9(2):135-40.

24. Ownby RL, Crocco E, Acevedo A, John V, Loewenstein D. Depression and risk for Alzheimer disease: systematic review, meta-analysis, and metaregression analysis. Arch Gen Psychiatry. 2006;63(5):530-8. DOI:10.1001/archpsyc.63.5.530

25. Pan A, Sun Q, Okereke OI, Rexrode KM, Hu FB. Depression and risk of stroke morbidity and mortality: a meta-analysis and systematic review. JAMA. 2011;306(11):1241-9. DOI:10.1001/jama.2011.1282

26. Pao H, Fu H. Renewable energy, non-renewable energy and economic growth in Brazil. Renew Sustain Energy Rev. 2013;25:381-92. DOI:10.1016/j.rser.2013.05.004

27. Penninx BW, Leveille S, Ferrucci L, Eijk JT, Guralnik JM. Exploring the effect of depression on physical disability: longitudinal evidence from the established populations for epidemiologic studies of the elderly. Am J Public Health. 1999;89(9):1346-52. DOI:10.2105/AJPH.89.9.1346

28. Reynolds SL, Haley WE, Kozlenko N. The impact of depressive symptoms and chronic diseases on active life expectancy in older Americans. Am / Geriatr Psychiatry. 2008;16(5):425-32.

DOI:10.1097/JGP.0b013e31816ff32e 
29. Romero-Ortuno R, Fouweather T, Jagger C. Cross-national disparities in sex differences in life expectancy with and without frailty. Age Ageing. 2014;43(2):222-8. DOl:10.1093/ageing/aft1 15

30. Wancata J, Alexandrowicz R, Marquart B, Weiss M, Friedrich F. The criterion validity of the Geriatric Depression Scale: a systematic review. Acta Psychiatr Scand. 2006;114(6):398-410. DOI:10.1111/j.1600-0447.2006.00888.x

31. Win S, Parakh K, Eze-Nliam CM, Gottdiener JS, Kop WJ, Ziegelstein RC. Depressive symptoms, physical inactivity and risk of cardiovascular mortality in older adults: the Cardiovascular Health Study. Heart. 2011;97(6):500-5. DOI:10.1136/hrt.2010.209767

32. Yaka E, Keskinoglu P, Ucku R, Yener GG, Tunca Z. Prevalence and risk factors of depression among community dwelling elderly. Arch Gerontol Geriatr. 2014;59(1):150-4. DOI:10.1016/j.archger.2014.03.014

33. Yesavage JA, Brink T, Rose TL, Lum O, Huang V, Adey M et al. Development and validation of a geriatric depression screening scale: a preliminary report. J Psychiatr Res. 1982;17(1):37-49. DOI:10.1016/0022-3956(82)90033-4

34. Zvolensky MJ, Bakhshaie J, Sheffer C, Perez A, Goodwin RD. Major depressive disorder and smoking relapse among adults in the United States: A 10-year, prospective investigation. Psychiatry Res. 2015;226(1):73-7. DOI:10.1016/j.psychres.2014.11.064

Funding: Fundação de Amparo à Pesquisa do Estado de São Paulo (FAPESP - Process 1999/05125 [wave 1]; 2005/54947-2 [wave 2]; 2009/53778-3 [wave 3]).

Authors' Contribution: Statistical analysis design and performance: FCDA. Data collection: MLL and YAOD. Manuscript drafting: FCDA and FW. Critical review of the manuscript for intellectual content: FCDA. All authors discussed the results, commented on the manuscript at all stages, and read and approved the final manuscript.

Conflict of Interest: The authors declare no conflict of interest. 